\title{
Suicide risk among general hospital inpatients
}

\author{
Jared F. Roush MA, Evan T. Guidry MA
}

Suicide is the tenth leading cause of death in the United States ${ }^{1}$ and a major public health concern. ${ }^{2}$ According to The Joint Commission, death by suicide represents one of the most commonly reported sentinel events. ${ }^{3}$ It is estimated that between $0.97 \%$ and $1.9 \%$ of all suicides occur in general hospitals, ${ }^{4}$ accounting for an estimated 5 to 15 patient deaths per 100,000 admissions in general hospitals. ${ }^{5,6}$ Although psychiatric consultations are appropriate and common for suicidal patients in nonpsychiatric units, 5 it is important for healthcare providers to competently assess for suicide risk and to take reasonable steps to ensure the safety of a suicidal patient. Therefore, we will provide an overview of the characteristics of inpatient suicide, evidence-based assessments that may be used to evaluate patients at risk for suicide, and post-discharge suicide risk management recommendations as it pertains to general hospital inpatients.

\section{ChARACTERISTICS OF INPATIENT SUICIDE}

The most common diagnoses associated with death by suicide in the general hospital are depressive disorders $(46 \%)$, substance-related disorders $(9.3 \%)$, and delirium $(7.4 \%))^{5}$ The most common nonpsychiatric medical diagnoses associated with inpatient death by suicide include malignancy $(38 \%)$, infectious disease (13\%), AIDS (8\%), and orthopedic conditions ( $8 \%) .{ }^{5}$ Risk for death by suicide is also associated with a greater number of previous suicide attempts. ${ }^{7}$ Other risk factors for suicidal behaviors in medical settings include previous suicide attempts, suicide ideation, family history of suicide, physical

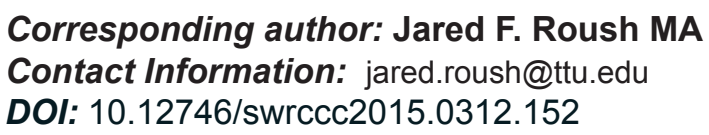

health problems (e.g., central nervous system disorders, chronic or intense acute pain), poor prognosis, social stressors, loss of independence, loneliness, and hopelessness. ${ }^{4}$ Warning signs associated with an imminent risk for suicide include irritability, increased anxiety, agitation, impulsivity, decreased emotional reaction, and refusal to eat or have visitors. ${ }^{7-9}$

Marked differences exist between the modal death by suicide of a general hospital inpatient and an inpatient in a psychiatric unit or hospital. Among inpatients who die by suicide, those in general medical hospitals are more likely to be older, married, and employed compared to those in psychiatric units. ${ }^{8}$ General medical inpatients who die by suicide are less likely to communicate suicide-related thoughts, but more are likely to engage in suicide attempts shortly after admission, to use violent methods for suicide, to die by suicide at night, and to have physical diagnoses, compared to psychiatric inpatients. ${ }^{5}$

The method of choice for death by suicide has also been examined among general hospital inpatients. The most common method is jumping (54\%), followed by hanging (16\%), cutting (12\%), firearm use $(10 \%)$, poisoning $(6 \%)$, and drowning $(2 \%) .{ }^{7}$ This is consistent with the most common method of jumping in psychiatric settings, but contrasts with the most common method of firearm use in the general population. ${ }^{7}$ Unfortunately, it is unknown what particular monitoring or observation protocols may have been in place at the time of suicide. Given the limited research examining methods for suicide in general hospital settings and the low base rate of suicidal behaviors, no unit-specific findings within general hospitals emerge from the extant literature. ${ }^{4,7}$ Any differences in the method of choice are likely to reflect disparities in access to lethal means between settings. 


\section{EVIDENCE-BASED SCREENING AND ASSESSMENT OF SUICIDE}

The SAD PERSONS mnemonic identifies risk for suicide by the presence of 10 risk factors: Sex, Age, Depression, Previous attempts, Ethanol abuse, Rational thinking loss, Support system loss, having an Organized plan, having No spouse, and having a terminal or severe chronic Sickness. ${ }^{10}$ While this mnemonic provides a very brief way to screen for suicide risk, it lacks specificity in predicting suicidal behaviors due to its reliance on broad risk factors. ${ }^{11}$ An alternative screening instrument is the IS PATH WARM mnemonic, which focuses on the presence of suicide Ideation, Substance abuse, feelings of Purposelessness, feelings of Anger, feeling Trapped, feelings of Hopelessness, Withdrawing from social circles, Anxiety, Recklessness, and Mood changes. ${ }^{11}$ A more thorough evidenced-based suicide risk assessment is the Suicide Status Form, a clinical assessment and treatment-planning tool that examines quantitative and qualitative aspects of psychological pain, stress, agitation, hopelessness, and self-hate using a 5-point ordinal response scale. ${ }^{12}$ Other important factors to consider when determining risk include a history of suicide attempts or non-suicidal self-injurious behaviors and access to firearms, as these risk factors are highly correlated with lethal or near-lethal suicide attempts and are consistent with theoretical models of suicidal behaviors. ${ }^{13,14}$

When formulating a plan for the safety of a patient reporting suicide ideation, it is important to understand that no-suicide contracts are not effective at helping patients cope or at reducing the risk for suicidal behaviors. ${ }^{15}$ On the other hand, crisis response plans have been repeatedly found to be more effective at reducing suicide risk. ${ }^{16-18} \mathrm{~A}$ crisis response plan is a document created collaboratively between the patient and healthcare provider that is most often comprised of the following domains: identifying warning signs and triggers for suicidal thoughts (e.g., people, places, objects, songs, times of the year), identifying coping strategies the patient can rely on in times of crisis (e.g., distraction techniques, relaxation techniques), friends and family members the patient can reach out to in a time of crisis, and professional agencies that can be contacted if the preceding steps do not reduce the patient's desire for suicide. ${ }^{18} \mathrm{Sev}$ eral options should be listed for each domain, with ideas primarily generated by the patient. ${ }^{16}$ The final step of the plan should include contact information for local emergency services including a local emergency room and a crisis hotline such as the National Suicide Prevention Lifeline (1-800-273-TALK). ${ }^{18}$ Healthcare providers, including psychologists, social workers, nurses, or physicians, who have a thorough understanding of the relevant domains that comprise a crisis response plan and the skills necessary to collaborate effectively with the patient are best suited to implement a crisis response plan.

\section{Post-DISChaRge SUICIDE RISK MANAGEMENT}

The heightened risk for post-discharge suicide is well documented and is typically greatest within the first week following discharge. ${ }^{19-21}$ The only suicide prevention strategy to effectively reduce post-discharge suicide in a randomized clinical trial is the Caring Letters Project, ${ }^{22,23}$ in which discharged patients at risk for suicide received brief, typed caring letters that included some basic personal information. The letters emphasized that staff remembered and had positive feelings toward the patient. The letters were sent every month for four months and then every four months for eight months. ${ }^{22}$ Patients who received the caring letters were more than twice as likely to not die by suicide during the first two years after discharge. ${ }^{22,23}$ This suicide prevention method can also be adapted to reflect advances in communication, as discharged patients have been found to generally prefer e-mail versus postal mail. ${ }^{22}$

Recommendations regarding the discharge process for suicidal inpatients have been made to reduce the occurrence of post-discharge suicide, which include psychoeducation with the patient and patient's family about suicide risk, potential triggers, and developing a crisis response plan for the patient to use as needed before he or she is connected with ongoing community-based mental health care. ${ }^{24}$ The discharge process should also include pre-discharge medication education and reconciliation, and postdischarge telephone follow-up within 72 hours of 
discharge to encourage the patient to connect with his or her outpatient provider. ${ }^{24}$ Due to the low adherence to mental health outpatient referrals, ${ }^{25}$ efforts should be made to help ensure that timely follow-up appointments with mental healthcare providers are kept. Specific recommendations regarding safe and effective prescribing practices at discharge include limiting the quantity of prescribed medications to only the amount required until a follow-up appointment, educating the patient's family about signs of clinical deterioration and potential overdose, and having the patient or patient's family dispose of unneeded medications. ${ }^{26}$

\section{Conclusion}

It is important for hospital staff, including physicians, nurses, and other allied health providers, to have an understanding of the characteristics of inpatient suicide, evidence-based suicide risk assessments, and prevention strategies for patients at risk for suicide. Although an understanding of risk factors is important to consider when assessing suicide risk, evidence-based suicide risk assessments and crisis response plans should be utilized for suicidal inpatients. Furthermore, care should be taken during the discharge process for a patient at high risk for suicide, given the heightened risk for death by suicide following discharge.

\footnotetext{
Author Affiliation: Jared F. Roush and Evan T. Guidry are clinical psychology doctoral students in the Department of Psychological Sciences at Texas Tech University in Lubbock, TX.

Received: $10 / 01 / 2015$

Accepted: 10/09/2015

Reviewers: Michael Phy DO, Steve Urban MD

Published electronically: 10/15/2015

Conflict of Interest Disclosures: None
}

\section{REFERENCES}

1. Centers for Disease Control and Prevention. Web-based injury statistics query and reporting system. http://webappa. cdc.gov/sasweb/ncipc/leadcaus10_us.html. Updated June 24, 2015. Accessed September 20, 2015.

2. U.S. Public Health Service. National Strategy for Suicide Prevention: Goals and Objectives for Action. http:// www.surgeongeneral.gov/library/reports/national-strategysuicide-prevention/full_report-rev.pdf. Published September 2012. Accessed September 20, 2015.

3. The Joint Commission. Summary Data of Sentinel Events Reviewed by The Joint Commission. http://www.jointcommission.org/assets/1/18/2004-2015_2Q_SE_Stats-Summary.pdf. Published July 9, 2015. Accessed September 20, 2015.

4. Tishler C L, Reiss N S. Inpatient suicide: Preventing a common sentinel event. Gen Hosp Psych 2009; 31:103-109. doi:10.1016/j.genhosppsych.2008.09.007

5. Cheng I, Hu F, Tseng M M. Inpatient suicide in a general hospital. Gen Hosp Psych 2009; 31:110-115. doi:10.1016/j. genhosppsych.2008.12.008

6. Shapiro S, Waltzer H. Successful suicides and serious attempts in a general hospital over 15-year period. Gen Hosp Psych 1980; 2: 118-126. doi: 10.1016/0163-8343(80)900250

7. Wint D P, Akil M. Suicidality in the General Hospitalized Patient. Hosp Physician 2006; 42(1):13-22.

8. Ballard E D, Henderson D, Lee L M, Bostwick J M, Rosenstein D L. Suicide in the medical setting. Joint Commission Journal on Quality and Patient Safety/Joint Commission Resources 2008; 34(8): 474.

9. Bostwick J M, Rackley S J. Completed suicide in medical/ surgical patients: who is risk? Current Psych Reports 2007, 9, 242-246. doi: 10.1007/s11920-007-0026-6

10. Patterson W, Dohn H, Bird J, Patterson G. Evaluation of suicidal patients: The SAD PERSONS Scale. Psychosomatics 1983; 24: 343-349.

11. Juhnke G A, Granello P F, Lebron-Striker M. IS PATH WARM? A suicide assessment mnemonic for counselors. (ACAPCD-03). 2007. Alexandria, VA: American Counseling Association.

12. Jobes D A. Managing suicidal risk: A collaborative approach. 2006. New York: Guilford Press.

13. Taliaferro L A, Oberstar J V, Borowsky I W. Prevention of youth suicide: The role of the primary care physician. J Clin Outcome Management 2012; 19: 270-285. Retrieved from: http://www.jcomjournal.com/

14. Van Orden K A, Witte T K, Cukrowicz K C, Braithwaite S R, Selby E A, Joiner Jr T E. The interpersonal theory of suicide. Psych Rev 2010; 117: 575. doi: 10.1037/a0018697 
15. Rudd M D, Mandrusiak M, Joiner T E. The case against no-suicide contracts: the commitment to treatment statement as a practice alternative. J Clin Psych 2006; 62: 243-251. doi: $10.1002 /$ jclp. 20227

16. Rudd M D, Joiner T E, Rajab M H. Treating suicidal behavior: An effective, time-limited approach. 2001. New York, New York: The Guilford Press.

17. Sher L, LaBode V. Teaching health care professionals about suicide safety planning. Psychiatria Danubina 2011; 23: 396-397.

18. Wenzel A, Brown G K, Beck A T. Cognitive therapy for suicidal patients: Scientific and clinical applications. 2009. Washington, DC: American Psychological Association.

19. Deisenhammer E A, Huber M, Kemmler G, Weiss E M, Hinterhuber H. Psychiatric hospitalizations during the last 12 months before suicide. Gen Hosp Psych 2007; 29: 63-65. doi:10.1016/j.genhosppsych.2006.09.007

20. Erlangsen A, Zarit S H, Tu X, Conwett Y. Suicide among older psychiatric inpatients: an evidence-based study of a high-risk group. Am J Geriatric Psychiatry 2006; 14: 734741. doi:10.1097/01.JGP.0000225084.16636.ec

21. Luxton D D, June JD, Comtois K A. Can postdischarge follow-up contacts prevent suicide and suicidal behavior? Crisis 2015; 34: 32-41. doi: 10.1027/0227-5910/a000158

22. Luxton D D, Kinn J T, June J D, Pierre L W, Reger M A, Gahm G A. Caring Letters Project: A military suicide-prevention pilot program. J Crisis Intervention Suicide Prevention 2012; 33: 5-12. doi:10.1027/0227-5910/a000093

23. Motto J A. Suicide prevention for high-risk persons who refuse treatment. Suicide and Life-Threatening Behavior 1976; 6: 223-230. doi: 10.1111/j.1943-278X.1976.tb00880.x

24. Loch A A. Discharged from a mental health admission ward: is it safe to go home? A review on the negative outcomes of psychiatric hospitalization. Psych Res Behavior Management 2014; 7. doi: 10.2147/PRBM.S35061

25. Lin C J, Lu H C, Sun F J, Fang C K, Wu S I, Liu S I. The characteristics, management, and aftercare of patients with suicide attempts who attended the emergency department of a general hospital in northern Taiwan. J Chinese Med Assn 2014; 77:317-324. doi: 10.1016/j.jcma.2014.02.014

26. Fernandes V, Flak E. Safe and effective prescribing practices at the point of discharge from an inpatient psychiatry unit. J Psych Practice 2012; 18:12-19. doi:10.1097/01. pra.0000410983.08229.d0 